\title{
Cyber Literature: Wattpad and Webnovel as Generation Z Reading in the Digital World
}

\author{
$1^{\text {st }}$ M. Yoesoef \\ Department of Literature, Faculty of Humanities \\ Universitas Indonesia, \\ Depok, Indonesia \\ yoesoev@yahoo.com
}

\begin{abstract}
The convergence of digital technology and information in the 4.0 revolution industry has given birth to a generation who grew up with devices, including both smartphones and computer devices (desktops, laptops). Well versed in the intricacies of social media, digital applications, and platforms, Generation $Z$ (Gen $Z$ ), also known as the digital natives, is a demographic group born in late the 1990s and early 2000s. In the 21 st century, they have become the largest group to access cyberspace. Their interactions within cyberspace also affect their reading culture. Reading materials in the form of literature are also developing in the virtual world. This recent development raises certain questions. First, how does Gen $Z$ appreciate literature in the midst of the frenzied information offered in cyberspace? Second, what kind of literature does this generation appreciate? These questions demand answers that are able to address a basic question: How does Gen $Z$ appreciate literature in cyberspace? Based on Internet searches, some literary works that can be accessed by Gen $Z$, among others, are in the format of Wattpad and Webnovel. Thus, further questions arise, such as what is the tendency of literary works published in cyberspace? Who are the writers? These questions link literature in cyberspace, its readers, its authors, and the Wattpad and Webnovel forums themselves. Based on these matters, this article discusses various literary expressions in cyberspace and their varied tendencies, which can then be categorized into types of popular literature. Research results and studies show that literary works that appear in Wattpad and Webnovel formats include poetry, short stories, and serial stories. In addition, there are blogs that specialize in documenting literary works such as drama literature. Through readings in the Wattpatt and Webnovel forums, it was found that in cyberspace literary works, there are aspects of creativity and potential shown by Gen $Z$ that underlie the potential for character formation, literary creativity, and innovation of the generation.
\end{abstract}

Keywords-appreciation, cyber, digital, cyberspace, generation $Z$, character, literacy.

\section{Introduction}

The development of digital technology over the last 20 years has fostered a generation that grew up with devices, including both smartphones and computer devices (desktops, laptops, and tablets). This generation accesses and very much depends upon information presented on these devices. They also communicate through high-tech equipment combined with the development of Internet-based information technology. Known as Gen Z, this generation is a demographic group that was born in and after 1995 and grew up in the 2000s. In the 21 st century, this generation earned the title of the digital natives.
As the main actors who have grown up together with the digital world, this generation certainly creates its own culture, especially in terms of accessing information and reading texts online. In terms of literary works in cyberspace, Gen $\mathrm{Z}$ is a very potential market in their own rights. Thus, two questions arise. First, how does this generation appreciate literary works in the midst of the frenetic information technology in cyberspace? Second, how are traces of Indonesian literature related to the character formation of Gen Z? These two significant questions are worth answering, at least to be able to show this generation's constellation with their literary works.

In the virtual world, literary works accessed by Gen Z, among others, are found on Wattpad, Webnovel, and blogs. Hence, more questions arise, namely what are the characteristics of the literary works published on mobile applications, and who are the writers? The previous two questions and the latter two create a link among cyberspace, Gen Z, and literary works. Therefore, this article attempts to describe various literary expressions in cyberspace, the genres, and the characteristics of digital literary works. The results of the research show that literary works in cyberspace include genres of poetry, short stories, and series of stories on Wattpad. In addition, there are blogs that specialize in documenting drama literature.

\section{Method}

This study examines two digital story reading applications: Wattpad and Webnovel. A literature study method was applied to describe the genres and characters of samples of stories in both applications. In addition, a sociological approach to literature was used to identify and discuss the sociological characteristics of the readers of each application and their implications for the reading culture of Gen Z.

\section{Result and Discussion}

In the field of literature, literary texts developed in cyberspace include, among others, the Wattpad website format and applications or blogs that specialize in posting literary works (poetry, short stories, serial stories, and drama). Literary works that are present in Wattpad (also available on www.Wattpad.com) and in its application format include a wide range of genres, such as chick-lit, short stories, fantasy, scientific fiction, fan fiction, teen fiction, historical fiction, general fiction, humor, horror, classic, action, werewolf, mystery, nonfiction, psychics, adventure, poetry, romance, spiritual, and vampire. Some 
examples include "words that never could be said" (poetry), "Cruel Flower" (historical fiction), "Me and My Best Friend" (teenage stories), "Stevra" (fantasy), "Love is Love" (fiction fans), and "Billionaire" (women's literature).

The Wattpad application itself is an Internet-based fiction story service platform that can be accessed by story writers and readers. It was originally used as an arena to connect unknown but talented writers with publishing companies or the world of global multimedia entertainment. Fiction publishers affiliated with this service include Macmillan, Wattpad Books, Harper Collins, and Simon Schuster; and in the entertainment and film sectors, NBC, Paramount Entertainment, Wattpad Studio, and One Turner. It is also built to connect writers with their readers. Through Wattpad, a cross-country and cross-continental community of 70 million has been built. The community relation consists of two categories. The first is the story writers and readers; the second is story writers and producers (publishing and film).

Thus, through these elements, a literary system (author literary work - reader) has been developed through a digitally connected network that is very dynamic. This can be seen from the interactions in the Wattpad forum, where readers can interact with the story writers through direct conversations. Even the Wattpad forum has held activities to improve community engagement, such as writing contests for awards and partnering with syndicated publishers or the global multimedia entertainment world. In terms of improving writing skills, there is an annual conference forum that offers guidance, support, and career-oriented programs.

In Indonesia, the Wattpad application is considered very popular among teenagers. This is indicated in the language used in the comment boxes and forums and the number of readers recorded for each story published on the application. For example, a story titled "Gadis Berandalan," written by niamajenang93 [1], consists of 71 parts and has currently been read by 8.2 million readers with a support vote totaling 245.000 (last accessed on August 3, 2019, at 14.38). This story is about Alex Bramastyo (Ali), a handsome, young, and rich businessman who is engaged to Regina Anastasya (Prily), the daughter of Alex's father's work colleague. An appealing note to attract the readers is "Would the world of Alex Bramantyo be destroyed by the presence of Regina Anastasya? Or just the opposite?" Alex has always dreamed of a beautiful, sexy, and elegant companion who is capable of accompanying him as a young entrepreneur, while Regina is a tomboyish and sloppy woman who does not care about the latest fashion or even her appearance. Soon, the story presents a conflict of relations between the two contrasting worlds. On the one hand, the image of a young, handsome, and rich businessman directs the reader to the ideal conditions of successful people in his field. Meanwhile, Regina is a girl whose life is far from disciplined and is rather chaotic. The two of them also belong to different social backgrounds. Alex lives in a social circle of entrepreneurs, while Regina lives in a dynamic world of youth. The contrast between the two characters is the main plot of this story. The author, Niamajenang, begins the story with an interesting prologue because it immediately provides an illustration for the two characters. She writes as follows.

"Mom, this is crazy! How come you want me to marry a sloppy girl like her! That would destroy my reputation as a cool guy," Ali protested.
“Ali, watch your words! You're embarrassing me!" said Ranti, Ali's mother.

"Do you really think I want to marry you? An arrogant guy like you doesn't deserve me!" Prily replied.

Both Ali and Prily's parents were frustrated. It looked like this matchmaking event was far from running according to their plan.

[...]

"It looks like their engagement must be carried out as soon as possible. Who knows, if they are engaged, they can get along well," said Widura, which was soon agreed by Prasetyo.

Eng ing eng ... Back again with my latest story. Huaaaa! Here, Prily plays the role of a shoddy girl with a slightly sloppy appearance ... While Ali plays the role of a cool guy, who has a particular pleasure in conquering really beautiful women ... Wooooo! This is a challenge for the writer ...

I hope you like it.

(Niamajenang, 2019)

The prologue illustrates the struggle of the figure of Alex (Ali), who tried to subdue his future wife, Prily. Such plots are clearly appealing for teenagers, who love romantic stories.

Another popular love story was "Catatan tentang Hujan" ("Notes on Rain"), which was written by Anindya Frista [2] and has been read 6.24 million times (by the time this article was written). This story tells of Senja (Dusk), Fajar (Dawn), and Langit (Sky). They are high school students who are involved in a love triangle. Senja is a girl who is not very popular in her class, but she is liked by Fajar, an indifferent boy who is very popular among the girls at school. On the other hand, there is Langit, who secretly likes Senja but does not want to come between Fajar and Senja. This story was published as of April 2, 2018, in print.

The interesting thing about the stories in the Wattpad application is the interactive forum that connects the writers and their readers. It was also found that sometimes there are conversations between the readers and the characters in the story in the forum. Additionally, writers sometimes share a spoiler of the next part or chapter of a story. The example in Figure 1 shows how the writer directs the readers to continue reading their story using very casual expressions as if uttered by a character in their story. For instance, "cieeee ... you continue scrolling. You still miss me, huh?!" expresses Fajar, who was in a comatose state in the last chapter of the story. The author also reminds the readers about the second novel of "Catatan tentang Hujan," which is the sequel of the story of Senja, Fajar, and Langit. This type of interaction can be seen on the right side of the picture where there are dialogue blocks containing numbers. The dialogue balloon with numbers shows readers' comments for the narrative part of the story, as can be seen in Figure 2. 


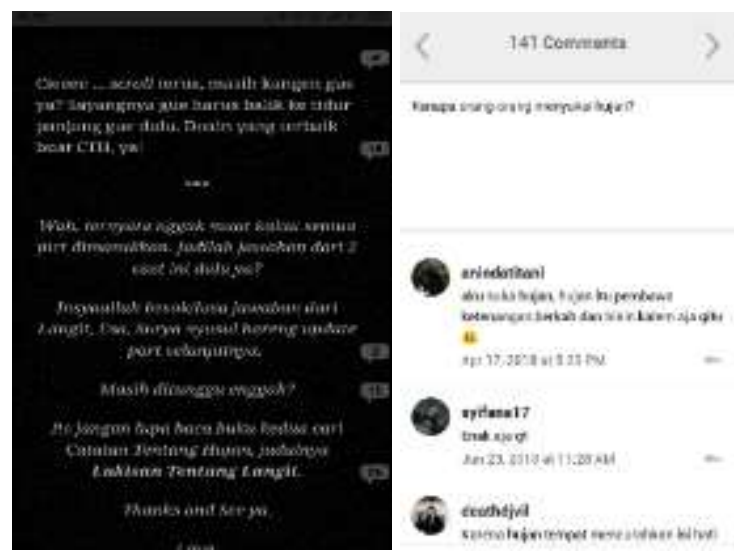

Fig. 1. Comments from writer and characters

Fig. 2. Comments from readers

Besides posting comments, authors can also post pictures of the characters in their stories as if it were the characters who were interacting with the readers, as seen in Figure 3.

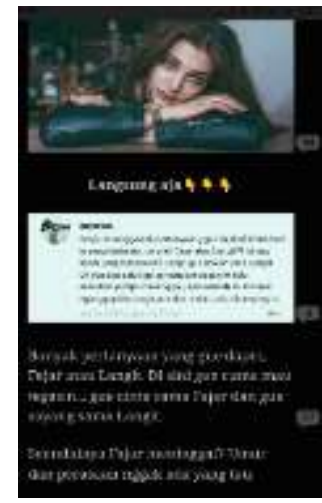

Fig. 3. Senja character

Senja, who is represented by a picture of a very beautiful girl, is asking some questions to the readers about how she should feel about her two friends, Fajar and Langit. Besides images, a character of a story can be presented in an audiovisual format. These types of features seem to bind readers and stories in Wattpad and are not found in the Webnovel application.

Stories in the Webnovel application are no different in terms of genre and include romance, horror, fantasy, adventure, mystery, drama, poetry, science fiction, action, and humor. However, since Webnovel readers are mostly adults, the stories are mostly about families, life in the work environment, and competition in work life. Hence, conflicts that occur are often about husband and wife relationships, infidelity, and love adventures. Moreover, the interactive features on Webnovel are not as extensive as those on Wattpad. It only provides a comment box at the end of each part or chapter of a story. Compared to Wattpad, the stories on Webnovel are less diverse. The following excerpt was taken from a story on www.webnovel.com titled "Terbelenggu" ("Shackled"). It is a horror story by Imelda Natasya [3] that consists of 57 parts (chapters). The story is about Tasya, a girl who must leave her lover (Dirga) to marry a man she does not know (Adamson). In her life, Tasya has to experience pain and suffering because she does not love her husband. As seen in the text below, some scenes of sexual violence are explicitly described.
Slowly, Adamson's lips touched Ana's. She couldn't resist him.

As their lips were touching, Adamson slowly transferred the food in his mouth into Ana's.

"Cuihhhh!!! You bastard!!!” Ana tried to break away from Adamson [...] With a swift motion Adamson squeezed his lips between mine. His right hand held my hands over my head while his other hand started groping me. Soon fear began to overtake me. Slowly, my tears were falling. But that psychopath ignored my cry, not even a slightest bit. In fact, he became more aggressive by slowly opening all the buttons of my shirt, revealing the parts of my chest.

(Natasya, 2019: 3)

As shown in the excerpt above, the types of relationships and the complexity of conflicts are different than those found on Wattpad. Therefore, literarily, the story characteristics of the two separate story applications differ according to their target audiences.

In addition to being published in print, a number of stories on Wattpad have also been made into films. An example of the success of this is the film After (released April 2019), which was written by Anna Todd and directed by Jenny Gage. This film was made at Wattpad Studio. In the Wattpad app, the story "After" has been read by more than one million people. It is the popularity of the story that drove film publishers and producers. It can be said that the development of Wattpad, which began as a vehicle for amateur writers, has advanced toward the publishing and entertainment industries (film). Syndication, however, did not occur on Webnovel. Therefore, Wattpad as a vehicle for the writer-reader-producer community has given birth to a business phenomenon that rightly targets Gen $\mathrm{Z}$ teenagers.

In Indonesia, the popularity of stories in the Wattpad application has not resulted in film production but is limited to publishing some of the stories into books. Among the stories that have successfully been published are Indigo Stories (Coconut Books, 2018), a horror story written by Hanamizuki Mega [4], and the novel Flesh Out (2017) by Bellazmur [5], which has been read by as many as 7 million readers on Wattpad. In addition, there is the novel Athlas [6], which has been read by 21.9 million Wattpad readers, by far the most widely read work up until 2019. Looking at the number of readers, it is no surprise that the publisher Mizan decided to print it. The huge market potential generated by Wattpad seems to be stimulating the publication of printed versions of Wattpad stories. Popular readings that are masspublished in major cities show the large reader market share is in large cities. In cities is where industrial culture and creative industries develop, as stated by Miles [7]. This also shows that the movement of the creative economy based on creative industries is interwoven due to the large market share, including the proliferation of various applications to complement entertainment and fun through devices.

The growing number of reading applications provided on Google Play Store or Apple Store is the result of the development of the latest generation of information and communication technologies (ICTs). ICTs have developed in such a way that they later became the basis for the occurrence of globalization and the 4.0 Industrial Revolution of today [8]. One form of ICTs' popularity in the era of the Industrial Revolution 4.0 is represented through the number 
of downloads of the Wattpad and Webnovel applications by users or readers. The applications have fundamentally changed the interactions and responses of writers and readers of fiction in this digital era. The global situation in the era of information technology continues to develop and give birth to cultural behavior that is in harmony with technological advancement. In Castells' perspective, as McGuigan [8] points out, it is in the interaction between technology and production, between experience and power. Thus, civilization, capital, and management changes are being restructured. Gen $\mathrm{Z}$, who is becoming familiar with technological developments such as artificial intelligence (AI), in its turn will compete with AI. Manufacturing systems that use robots to produce cars, for example, have replaced a lot of human labor. However, the presence of fiction writers will not be replaced by artificial intelligence created by humans. The ability of imagination represented through literary works still remains the legacy of humanity.

Through the legacy of their imagination, writers create a variety of fictional creativity that transcends even reality itself. Creativity opens up many possibilities to be spread through various technological formats and media publications in the digital world that are available now. Thus, the network that is built is able to stimulate the birth of creativity with economic value as a cultural and creative industry. Reading in the digital era apparently not only transforms digital media as sources of information but also changes the reading habits and reading-writing culture of Gen Z. User interface and human interactions in ICTs have opened rooms to many possibilities in the world of literary works and reading culture and consumption worldwide.

\section{Conclusion}

Gen Z, who lives, grows, and develops in a world mediated by ICTs, has one distinct characteristic, which is that they create their own culture that is identifiable with the digital era in which they live. At the other end, information technology-based cultural industry also develops to serve their need, thus producing a variety of cultural products that are consumed by its users, especially among Gen Z. One of them is related to reading culture and literary works. This generation's reading culture is no longer dictated by bestseller books or novels or book signings at bookstores. As current readers, they can choose to read any genre they like without leaving their own room, and as writers, they can now create their own literary works and make them available online, bypassing publishing companies and gaining direct feedback from their readers in real time. The texts uploaded on the Internet are no longer limited to verbal texts but are also presented in a multimedia text format.

In addition, in the fiction reading format, there are applications (and websites), such as Wattpad and Webnovel. Both of these fiction reading applications exist as interactive vehicles among writer-reader-publisher-producer. Writers of cyber fictions are generally amateur writers who are trying to tell stories through such media. A writer's creativity is also stimulated by his/her readers through comments and criticisms that are fed into the forum. Thus, interaction occurs not only between the writer and the reader but also between the reader and the fictional characters in the story. This phenomenon is highly developed in Wattpad, but it is less developed in web hosting. In fact, in Wattpad, a story is interspersed with pictures and videos depicting the characters.

A story's popularity on Wattpad also has an impact on publishers to print the story as a book. In that case, the publishers get the story and bring the author into the world of teenage reading. However, this did not happen to the authors on the web application. In America, a writer on Wattpad has the opportunity to publish his/her work in widescreen movie format. This certainly shows that Gen $\mathrm{Z}$ is a potential market share for entertainment business processing. In Indonesia, it is still limited to editing books.

The Industrial Revolution 4.0, which has been going on for two decades, has given rise to a generation that is familiar with information technology that has directly developed a reading culture that differs from that of the previous generation (Generation $\mathrm{Y}$ and the Millennial Generation). Castells [9] says that the networking paradigm (networking) is the application of economic and cultural processes that give attention to the attachment between economic fields, which then give birth to cultural behavior, especially culture with high technology. This is based on the thinking of McLuhan (1941) regarding technological culture (cultural technology).

In the nutshell, fiction reading in the digital world fosters a creative collaboration among creative industry players that develops by utilizing ICTs, which are increasingly accessed openly by people who have digital literacy.

\section{REFERENCES}

[1] Niamajenang93 (2019). "Gadis Berandalan (The Delinquent Girl)," Retrieved from Wattpad (www.Wattpad.com)

[2] Frista, Anindyta (2018). "Catatan tentang Hujan (Notes on Rain)." Retrieved from Wattpad (www.Wattpad.com)

[3] Natasya, Imelda (2019). "Terbelenggu (Shackled)." Retrieved from Webnovel (www.webnovel.com)

[4] Mega, Hanamizuki. (2018). Indigo Stories. Depok: Coconut Books.

[5] Bellazmur. (2017). Flesh Out. Jakarta: PT Gramedia Widiasarana.

[6] Kokoh, Kata. (2018). Athlas. Bandung: PT Mizan Pustaka.

[7] Miles, Malcom (2007). Cities and Cultures. New York: Routledge.

[8] McGuigan. (2006). Modernity and Postmodern Culture (Second Edition). New York: Open University Press.

[9] Castells, M. (1989). The Informational City: Information Technology, Economic Restructuring and Urban-Regional Process. Oxford and Cambridge, Mass: Blackwell.

[10] Assmann, Aleida, (2006). "The Printing Press and the Internet: From a Culture of Memory to a Culture of Attention," in Globalization, Cultural Identitites and Media Representations (Natascha Gentz and Stefan Kramer, eds.). Albany: State University of New York Press, p. $11-24$ 